\title{
Accessible by design: Applying UDL principles in a first year undergraduate course
}

\author{
Kari L. Kumar \\ University of Manitoba \\ Maureen Wideman \\ University of the Fraser Valley
}

\begin{abstract}
This article presents a case study of a technology-enhanced face-to-face health sciences course in which the principles of Universal Design for Learning (UDL) were applied. Students were offered a variety of means of representation, engagement, and expression throughout the course, and were surveyed and interviewed at the end of the term to identify how the UDLinspired course attributes influenced their perceptions of course accessibility. Students responded very positively to the course design, and felt that the weaving of UDL throughout the course resulted in increased flexibility, social presence, reduced stress, and enhanced success. Overall, students felt more in control of their own learning process and empowered to make personal choices to best support their own learning. This course design also led to increased satisfaction from the perspective of the instructor and reduced the need for intervention by the campus disability services department.
\end{abstract}

\section{Résumé}

Le présent article propose l'étude de cas d'un cours individuel de sciences de la santé où l'apprentissage est amélioré par les technologies et dans lequel les principes de conception universelle de l'apprentissage étaient mis en pratique. On offrait ainsi aux étudiants une variété de moyens de représentation, d'engagement et d'expression tout au long du cours puis, à la fin du trimestre, ces mêmes étudiants étaient sondés et interviewés afin 
de déterminer comment les attributs de ce cours inspiré de la conception universelle de l'apprentissage avaient influencé leurs perceptions envers l'accessibilité au cours. Les étudiants ont répondu favorablement à la conception du cours et, pour eux, les entrecroisements de la conception universelle de l'apprentissage exposés tout au long du cours ont amélioré la flexibilité et la présence sociale, ont réduit le taux de stress et ont haussé le taux de réussite. Dans l'ensemble, les étudiants sentaient qu'ils contrôlaient mieux leur propre processus d'apprentissage et qu'ils étaient habilités à faire des choix personnels afin de mieux soutenir leur propre apprentissage. Cette conception de cours a également mené à une plus grande satisfaction du point de vue de l'instructeur et a réduit le besoin en intervention par le département des services de soutien à l'invalidité du campus.

\section{Introduction}

The student body is becoming increasingly diverse in higher education. For example, students with disabilities are attending higher education in increasing numbers in Canada and the US (American Council on Education, 2005; Fichten, Jorgensen, Havel, \& Barile, 2006; National Center for Education Statistics, 2011; National Council on Disability, 2003; U.S. Government Accountability Office, 2009). While enhanced diversity in the classroom may lead to an enriched learning environment as a result of a wide variety of student perspectives (American Association of University Professors, 2000), this also underscores the need for instruction to take into account diverse learning needs of the students. In order for a learning environment to be inclusive of the needs of all learners, the learning materials and an understanding of the learning materials must be accessible to all learners (Sapp, 2009). However, accessibility can be difficult to define and achieve because it is a somewhat subjective variable. This is because what is accessible to one student may not be accessible to another. To this end, application of the Universal Design framework to education holds much promise in helping educators design learning environments that are maximally accessible for diverse learner populations.

\section{Universal Design and Education}

The Universal Design (UD) movement originated in the field of architecture and its conception is generally credited to the late Ronald Mace. Mace envisioned UD as a practice to promote the design of physical spaces in a manner that would make them accessible to the widest number of patrons, including people with and without disabilities (Wilkoff \& Abed, 1994). For example, curb cuts in sidewalks are beneficial to wheelchair users, mothers with baby strollers and, more recently, to those of us who prefer to carry our schoolbooks in bags with wheels rather than backpacks. Essentially, the essence of UD is to promote proactively designing for inclusion.

In 1998, Orkwis and McLane released a report that described how the notion of UD may be highly valuable in the field of education. In 2002, the U.S. non-profit organization Center for Applied Special Technology (CAST) published their iteration of UD for education, which they refer to as Universal Design for Learning, UDL (Rose \& Meyer, 2002). This publication of the UDL framework was a reflection of a shifting mandate for CAST 
from developing assistive technologies for $\mathrm{K}-12$ education, towards considering how to instead adapt the curriculum to support diverse learner needs. The three UDL guiding principles of providing multiple means of representation, expression, and engagement are intended to reflect learner differences across recognition, strategic, and affective learning networks, respectively. Associated with these three overarching principles are specific guidelines intended to serve as a guiding framework for instruction (CAST, 2011).

In this paper, we will use the initials UDL when describing our own efforts at creating inclusive learning environments. We are most drawn to the UDL framework because of its emphasis on the learner and its roots in the neuroscience of learning.

\section{UDL in Higher Education}

CAST has also expanded its work to include higher education. Many other institutions of higher education in Canada and abroad continue to promote UDL (or a related iteration) as a useful instructional design framework, because references to UDL and related resources are commonly found on postsecondary teaching and learning websites. There is also increasing interest in harnessing the potential flexibility inherent in learning technologies to support UDL in higher education (for example, refer to the DO-IT program led by Sheryl Burgstahler at the University of Washington; http://www.washington.edu/doit/).

In the academic community, it stands to reason that faculty and institutional buy-in with respect to UDL would be furthered by strong evidence of its effectiveness. A recent review of the literature on UDL in higher education by Roberts Park, Brown, and Cook (2011) further highlights the need for more evidence of its impact. The authors of that study found only eight peer-reviewed articles that met their criteria for inclusion in their examination of empirical studies (experimental, qualitative, or mixed methods) on UDL. While several of these studies did provide evidence to validate the use of UDL in higher education such as the ability to improve student learning, engagement, and satisfaction (McGuire-Schwartz \& Arndt, 2007; Parker, Robinson, \& Hannafin, 2007), the literature base is nascent (Roberts et al., 2011).

\section{This Study}

This study was conducted to contribute to the growing literature base on UDL in higher education, by exploring how UDL might be practically achieved and how students respond to UDL-inspired course attributes. We present a case study conducted at an Ontario university in which the impact of UDL implementation in a first-year undergraduate course was examined from the perspective of the instructor (the first author), the students, and a disability service provider (the second author, who has previously had a role in faculty development at the same university). Also noteworthy is the technologyforward stance of the university and recently implemented provincial legislation, the Accessibility for Ontarians with Disabilities Act (AODA), which is relevant to higher education in the province. The AODA is aimed at enhancing accessibility in the province, and includes a Customer Service Standard and Integrated Accessibility Standards. These standards mandate that all physical spaces, services, and electronic learning spaces are accessible to all. An additional role of the second author is overseeing implementation of the AODA at this university. 
The first author has taught within an RPN to BScN program at the university. This program attracts primarily female students, and there is a large degree of diversity amongst the students with respect to their country of birth, first language, prior university experience, and age. Many of the students who enrol in the program are mature students who have not engaged in higher education for several years, although there are also a handful of students who enter the program directly following completion of a college RPN diploma program. The case study presented in this paper is of a technology-enhanced face-to-face science course that the first author has taught to RPN to BScN students for the past four years. This course is taken in the first semester of the program, and is one of the first university courses that the students are exposed to.

Over the past four years, efforts have been made to weave the principles of UDL into the design of this science course (as first described in Kumar, 2010). This follow-up study describes additional course modifications intended to achieve UDL and meet AODA requirements, and the study was expanded to include the perspective of students, faculty development, and disability services. We conducted this study to answer the following question: Does UDL-inspired course design correlate with enhanced accessibility of the course as perceived by the students?

\section{Theoretical Framework}

We view UDL as an instructional framework that may promote development of an inclusive learning environment in which all students have an equitable opportunity to succeed. To this end, a key ingredient of inclusiveness is accessibility-students must be able to both access and comprehend course materials in order to learn and must be offered means of expressing their learning that is accessible to them.

The theoretical lens with which we examine the data in this study is informed by critical disability studies. In disability theory, two models of disability are dominant: the medical model and the social model. Most postsecondary institutions still organize their services for students with disabilities around the medical model, where accommodations must be made to ensure the student with the disability is able to access the set curriculum. In the medical model, the student initiates the need for services by registering with the office of disability services and providing documentation to support the diagnosis of a disability. The student may participate as a member of a team with a learning strategist and a faculty member in order to make adjustments in delivery, assignment design, or evaluations that ensure the student can gain access to the materials (Areheart, 2008; Hadley, 2011). With the medical model, it is the student with the disability who must overcome shortcomings to participate in learning (Aerheart, 2008). This may require alternative formats for books and materials, note takers, captioning of videos and transcripts, and provision for extended time to complete tests and exams.

While most courses at the university of this study provide accommodations to courses under the medical model of disability, in this study the social model of disability informed the course design. First articulated in scholarly terms by Michael Oliver (Oliver, 1996), the social model of disability posits that disability arises as a result of socially constructed barriers rather than factors intrinsic to the individual. Some have argued that the social model of disability is incomplete because it does not address corporeal (bodily) aspects of disability, such as emotional consequences, pain, and fatigue (Hughes \& Paterson, 1997; 
Terzi, 2004). However, in spite of limitations of the model, it is useful in this context because it prompts consideration that accessibility (and thus inclusiveness and UDL) is important for all students. This is because the social model of disability contends that students are who they are, and if they are not able to access course materials, then it is the course that must be altered, rather than the student (Rose, Harbour, Johnston, Daley, \& Abarbanell, 2006) The barrier to education comes not from the student with the disability but from a learning environment that is exclusive in its design and delivery. The process of setting accommodations for each student, for each course, for each semester is seen as an inefficient and ineffective approach to course delivery (Houghton \& Fovet, 2012). The social model of disability, however, is aligned with the key premise of UDL, which is to shift the burden of adaptability from the shoulders of the students to the learning environment (Rose \& Meyer, 2002). UDL is seen as a sustainable approach that advocates a change in the course design and delivery methods to ensure greater flexibility where more students can benefit (Harrison, 2006).

\section{Method}

This study was conducted during the fall academic session. There were 50 students enrolled in this offering of the course: 45 female and 5 male students. At the beginning of the term, one female student disclosed to the instructor that she had registered with the campus disability services office so that she would become eligible for academic accommodations. A second female student discussed a disability with the instructor but chose not to formally register with the campus disability services office.

The course instructor developed the course with UDL-inspired attributes and materials. This approach considered how to offer maximum flexibility with respect to how the course material was displayed or delivered and included methods of in-class instruction, use of the learning management system, WebCT, and how students were asked to express their understanding. This was intended to embody the overarching UDL principles of multiple means of representation, expression, and engagement. WebCT was used extensively to post learning materials and to engage in informal asynchronous discussion via the discussion board tool. To prepare accessible electronic course materials (including PDFs and Microsoft Office documents and presentations), the WebAIM online resources (http://webaim.org/articles) and books (Coombs, 2010; Grace \& Gravestock, 2009) were consulted. The Camtasia software (http://techsmith.com) was used to prepare videos, including an online lecturette for one course topic, a sample oral presentation, and a presentation tutorial video. Text for the videos was provided by captions and/or transcripts.

At the end of the course, we asked students for feedback about UDL-inspired aspects of the course. The second author (who had no relationship to the students) visited the last class of the term and extended an oral invitation to the class to participate in the study. It was explained to the students that approval for the study was obtained from the Research Ethics Board of the university, that participation in the study was voluntary, and that the course instructor would not see any of the data until after final grades for the course were submitted. Pseudonyms were assigned by the second author prior to sharing the data with the course instructor in order to protect anonymity of participants. Students were invited to contact either author following completion of the study if they were interested in obtaining a summary of the results. 
Participation involved completion of a 20-minute in-class questionnaire (see Appen$\operatorname{dix} \mathrm{A}$ ) and/or agreeing to be interviewed by the second author (see Appendix B). In keeping with the spirit of UDL, we offered students choices with respect to how the interviews were conducted (in person, over the telephone, or by email). No compensation was offered for participation in the study.

In-class questionnaire results were collated and interviews were transcribed and coded to identify themes. These themes were analyzed and reflected upon.

\section{Course Design and Rationale}

The following sections describe the course as it appeared the fourth time it was taught by the instructor. The course was not modified extensively for this course offering in order to adhere to UDL principles. Rather, UDL-inspired features were gradually added to the course over several offerings, and the version described below is the most recent iteration.

Multiple means of representation. To provide multiple means of representation, course materials were presented in multiple formats.

For each major course topic the instructor posted a PowerPoint file (and equivalent PDF version), a study guide (including a detailed point-form outline of the entire topic and a list of key concepts), and set up a topic-specific discussion forum at least 48 hours before the relevant class session within WebCT. These materials were posted to provide the students with note taking and study aids in different formats and to provide students with a means of discussing course materials outside of class time. Making these items available prior to the start of the class session was intended to allow students the option of previewing and/or printing class materials, and to reduce student anxiety by providing a blueprint for each class session ahead of time.

The instructor also included a variety of methods of presenting material to students in weekly in-class sessions, including use of PowerPoint slides, hands-on demonstrations with student volunteers, display of videos, a class discussion, and small-group discussion. One topic (microbiology) was presented as an online lecturette, which was presented in WebCT as a screencast, along with a transcript. These methods of presentation were intended to accommodate the learning needs or preferences of students according to selfreported characteristics that they shared with the instructor in their Student Profiles (see "Multiple means of engagement" below).

Through WebCT and the use of technology supported by the university, the instructor was also able to describe assessment requirements in a variety of ways. For example, she provided a detailed, text-based description of assignment requirements, the grading rubrics, and samples of completed assignments. One major assessment was a conferencestyle group presentation (Kumar, 2011). For this, the instructor provided a text-based description of the assignment and rubrics, and samples of the two different forms of presentations that students could choose from (an oral or a poster presentation). For the oral presentation example, she provided PowerPoint slides, a screencast, and a transcript. For the poster presentation example, she provided a PowerPoint poster slide, a text-only version of the poster content, a captioned screencast tutorial demonstrating how to create a poster in PowerPoint, and a transcript. This variety of methods of representation was intended to offer students multiple means of understanding assessment expectations. 
Multiple means of expression. Choices were built into all assessments in the course to allow students multiple means of expressing their understanding or viewpoint. Students were required to complete a midterm exam, final exam, written report, and presentation. The midterm and final exams included a variety of question styles. Moreover, there were options associated with many of the written questions that allowed students to choose which questions they felt most comfortable addressing, and they could address the questions in the manner they preferred. For example, students were offered the opportunity to express their understanding of concepts in chemistry by providing a chemical equation or by using words. For other topics, students were given the option of providing a labelled diagram, a text-only response, or a combination of both.

The instructor asked students to form groups to discuss the written report and to choose a due date and topic, and then to decide whether they would like to proceed as a group or independently. These instructions were intended to ensure that all students had the opportunity to discuss the report with peers (regardless of whether they had friends in the class), to choose the topic they were most interested in, and to choose a due date that best fit their personal and academic schedules. Students were required to work collaboratively on the presentation assignment (due to the large class size of approximately 50 students and time constraints), though they could choose the date, topic, and format they would like to use to make the presentation. In order to provide formative assessment and tolerance for error, students were encouraged to discuss drafts of their work with the instructor prior to submission of the final version of their written report, poster presentation, and/or oral presentation slides.

During oral presentations, student groups structured their presentations around accompanying PowerPoint slides. There were also many ways (unsolicited by the instructor) in which the students incorporated multimodal means of expression into their presentations. For example, one group included a brief skit at the beginning of the presentation, a second group performed a song and dance that they wrote during their presentation, and two groups brought props to help them explain concepts during their presentation. In addition, several groups included interactive question and answer periods with the audience to highlight key points from their presentation and enhance audience engagement. One of the groups that prepared a poster presentation also created an online screencast where they recorded one group member who provided additional oral explanations of key concepts while PowerPoint slides were displayed.

Students were given the option of completing up to four short assignments. By deciding whether or not to complete the optional short assignments, students could decide how much their final exam was worth since each optional assignment could reduce the final exam weighting. Although the optional assignments were posted on WebCT at the onset of the term, class time was also provided for students to work on them. If they were unable to finish them in class, students could complete them as homework and submit them through WebCT.

Each assignment was unique in order to add variety to the course and broaden students' skills. Assignment One asked students to comment on what they felt most and least confident with from a particular in-class session and prompted them to describe multiple strategies that they could take to seek answers to lingering questions. A wide variety of strategies, including working collaboratively with a peer, reading the course textbook, 
searching the Internet, using the WebCT discussion board, and speaking with the course instructor, were described by students.

Assignment Two required students to submit their notes from one class session either in hard copy or by posting electronically to the WebCT discussion forum. This assignment was inspired by a technique described by Rose et al. (2006) and was intended to provide students with multiple representations of understandings of the same class. It also allowed the instructor to provide individualized formative feedback to students. Class notes submitted from different students for the same class session varied widely in style. For example, some were composed entirely of text, while others included diagrams drawn by the students. Some students also included additional supporting information or examples taken either from the course textbook or their own clinical experience. One student used colour to convey meaning in her notes (e.g., highlighting key concepts in one highlighter colour and supporting examples in another colour).

Assignment Three required students to answer questions based on a detail-oriented course topic in lieu of closed-book exam questions on the topic. Finally, Assignment Four was a reflective paragraph that students wrote following a class discussion about the pros and cons of vaccination. Nearly all students $(86 \% ; N=43)$ completed all the optional assignments, while $12 \%(N=6)$ of the students completed three assignments, and a single student completed just one assignment.

Multiple means of engagement. The instructor attempted to engage the students in the course during the face-to-face sessions as well as within the learning management system (LMS). The week prior to the start of the class, she emailed all students with a welcome message and an invitation to complete a Student Profile to tell her about their interests and learning needs, and to initiate one-on-one interaction. This was intended to open the lines of communication between students and the instructor and to convey to the students that their individual needs were important. It also provided the instructor with insight regarding methods of representation that might best appeal to the class (see "Multiple means of representation" above). Students could engage in discussion with her and their peers in face-to-face class sessions, as well as by email and on ungraded discussion forums within WebCT (which were periodically seeded with links to relevant news stories, online learning tools, or suggested review questions to discuss). In face-to-face class sessions, the instructor prompted the students for their perspective on course topics (e.g., relevant clinical nursing experience). By imparting choices into the course assessments, it was hoped that students felt empowered to make choices according to their interests and past experiences.

\section{Results}

Thirty-five questionnaires were completed, but not all students completed every section or every question. The results are compiled based on the responses received for each question. Two students self-identified as having a disability.

Part One of the survey asked the students to indicate from a list which course materials they accessed and whether they found them helpful in their studies.

- 97\% accessed the text descriptions of images in the PowerPoint files and found them helpful.

- $97 \%$ accessed the detailed topic outlines in the study guides, with $94 \%$ of respondents finding them helpful. 
- $97 \%$ accessed the lists of key concepts in the study guides and found them helpful.

- $91 \%$ accessed the PDF printer-friendly version of PowerPoint slides, and $97 \%$ of the respondents found them helpful.

Some of the additional comments were

[With the PowerPoint files], I was able to follow along in class and add my own notes directly to the PowerPoint file.

[Using PowerPoint files] made note taking simple and was very easy to understand. Also helpful for exam preparation.

[The text descriptions of images in the PowerPoint files were most helpful] because in science we are studying the structures and functions from smaller unit[s] to a larger unit[s] (cells to body systems) and it's very important to know parts through images before you can relate to its function.

[The study guide] allowed us to learn more about what was discussed in class on our own time [and] at our own pace.

On the video lecture on microbiology,

- $83 \%$ watched the video recording of the microbiology lecture and all found it helpful.

- $89 \%$ of students accessed the transcript of the microbiology lectures and all found it helpful.

One student stated,

The course material I accessed was the transcript of the microbiology lecture. Even with all the oral presentations on microbiology, I was still lost. However, once I read the PowerPoint slide on microbiology, I felt relieved. The [transcribed] lecture on microbiology had increased my confidence for the final exam because I felt the oral presentation was not enough to prepare.

The instructor provided several methods to access a description of a poster assignment.

- $83 \%$ accessed the text-only version, and $88 \%$ of those respondents found it helpful.

- $60 \%$ used the video poster web tutorial, and $75 \%$ of those found it helpful.

- $60 \%$ used the captions of the poster web tutorial, and $76 \%$ of those found them helpful.

- $66 \%$ accessed the transcript of the web tutorial, and $80 \%$ of those found them helpful.

The second part of the questionnaire asked students, which course attributes, in their opinion, had a positive impact on their learning, a negative impact, or no impact. 
Table 1

Student Perceptions of the Impact of Course Attributes on Their Learning

\begin{tabular}{lrrr}
\hline Course Attribute & \multicolumn{3}{c}{ Impact } \\
\cline { 2 - 4 } & $\%+$ & $\%-\quad \begin{array}{c}\% \\
\text { None }\end{array}$ \\
\hline Choices for written report due dates & 91 & o & 9 \\
Choice to work independently or collaboratively on some assessments & 97 & 0 & 3 \\
Choice for presentation format (oral or poster presentation) & 94 & 3 & 3 \\
Choice for presentation date & 88 & 0 & 12 \\
Posting of class notes and study guide prior to the relevant class & 100 & 0 & 0 \\
Repetitive organization format of course materials WebCT pages & 94 & 0 & 6 \\
$\begin{array}{l}\text { Ability to choose whether to complete optional activities or write a } \\
\text { final exam worth more marks }\end{array}$ & 100 & 0 & 0 \\
$\begin{array}{l}\text { Instructor's request to submit a Student Profile form at the beginning } \\
\text { of the term }\end{array}$ & 74 & 5 & 21 \\
\hline
\end{tabular}

Note. Data is presented as the percentage of responses that fell into each impact category.

$+=$ positive impact

$-=$ negative impact

none $=$ no impact.

The student comments in the second section overwhelmingly stated that choice was their most helpful course attribute, whether it was a choice of due dates, a choice to work independently or collaboratively, or a choice to do additional assignments to reduce the exam final mark. The following were some of the comments received:

As a full-time student, I do work full time as well. Having the option to work independently was the most flexible options for me.

Being able to decide whether or not to complete these assignments helped to reduce the overwhelming feeling associated with having multiple (mandatory) assignments due.

Not everyone performs well on examinations-this gives opportunity to excel in other ways.

[Having choices] allowed me to gain marks and study useful information in a focused way; tests are not always my strong area so I could demonstrate I understood content. 


\section{The Interviews}

Following the questionnaire, four students came forward to continue their participation in the research through interviews. Based on an interview guide, the participants were asked a series of basic questions intended to prompt further discussion about accessibility of the course. The guide also allowed for additional comments and clarification as the interviews proceeded. Three students were interviewed over the telephone and recorded, one was interviewed through email. The recorded interviews were transcribed. In text form, the interviews were analyzed for common themes. For three of the four students, English was their second language. One interview participant self-identified having a learning disability.

In analyzing the text, the researchers identified four major themes that emerged from the interviews-flexibility, social presence, stress, and success.

Flexibility. As with the survey, the interview participants stated that the flexibility in the course and the ability to choose due dates, assignments, and group or individual work were key factors that contributed to their learning in this course. Many of the students in the program work full or part time in the health care field, and one student stated that being able to go online during a break and access course materials was very beneficial.

Another student, Ava, described how she liked having the choice of completing an assignment with a group or as an individual. If there was a topic she wanted to learn about and others didn't, she would choose to do the assignment on her own. "I choose papers based upon the subject or idea that I find interesting and I want to learn about more. Others may not want to learn about that or they may not find it as interesting as I did." Student Cheryl, found the course accessible "at different levels, in all different learning styles." She continued, [with flexible learning], you can choose which option would be best for you and the option that would be best for your learning. So, I'd say flexible learning is definitely a huge asset to any program." She also stated that the flexibility in deadlines enabled her to schedule her time and assignments around the obligations with her other courses. "What's really important to me, especially with time management and having a larger course load is to be able to anticipate exactly what's going to be in the program, what the expectations are to be successful."

Social Presence. Students commented on the amount of interaction they had with each other, with the materials, and with the instructor. What is evident from the responses was the importance students placed on being able to contact the instructor outside of class time and the speed at which she responded to the enquiries. Although interaction with the instructor is considered an aspect of the UDL principle for multiple means of engagement, this instructor's responsiveness to students also played an important role in students' abilities to access and understand materials, complete assignments, and reduce stress.

The discussion board played an important role and helped reduce intimidation that comes with asking questions in class. The discussion board provided an opportunity to engage in ungraded peer discussions on selected topics. It also enabled students to post questions and have them answered by fellow students or the instructor. Cheryl stated, "A lot of our classmates, they'd posted questions that they found from the study guide and she [the instructor] would answer them or she'd help you along with the questions that we had difficulty with so the discussion board was really good." Mariella stated, 
[The instructor] answers you as soon as you ask her a question. You don't even need to get away from the computer, you have your answer. So everything is there ... She knows you will be busy at this time because of midterms. She really prepares you for what's coming next. It's really like she takes your hand. She guides you, which is very good.

Ava, who has a learning disability, described how online and in-class discussions assist in her learning.

It's important because then I tend to retain that information because then you could be like, "yeah, that was discussed in class." Whereas, if it was just one person giving the information, it's not as good. I mean, some people learn best that way and some don't.

Stress. Postsecondary education, particularly in health sciences, can be a stressful experience (Wideman, 2011). Stress was a common theme as students described how they went to school full time, worked full time, or commuted over an hour each way to get to school. Students explained how the course design and organization greatly reduced their stress. Study guides for readings provided specifics on what was important to learn and what were the key questions to answer. Cheryl said,

With the large bulk of the material that was presented, I was able to narrow my focus, instead of just reading a chapter and hoping that I'm catching all the key elements. I was able to focus on which ones were crucial, and study and really understand them.

The flexibility of deadlines enabled students to plan their workload around the requirements of other classes they were taking. The final exam is generally a very stressful time for students, but they could plan to reduce the weight of the final exam by completing additional assignments earlier in the semester. Materials such as the presentations, notes, videos, and readings were available well before class time where students could access the materials, make notes, and prepare questions for class. Detailed assignment descriptions with accompanying rubrics available on the first day of class provided students with the necessary requirements. The students described how the consistency of how course material was prepared reduced their frustrations, since they knew what to expect. Mariella stated,

It's my first time I'm doing this in university and French is my first language. And when I'm doing it in a different language, I was like panicking every time. And to pass this class-honestly, it's the way [the instructor] gives the material that makes it so easy.

Success. The students participating in the interviews agreed that the UDL-designed course contributed to their success. The researcher enabled each participant to define his or her own version of success. For two of the students, they measured success in terms of marks, saying they felt their marks in this course were higher as a result of the way it was designed. For the other participants, they measured success in being able to understand the materials. Mariella, for example, felt that the anatomy and physiology component would be the most difficult unit in the course, but she said, 
The material is very heavy, but in the way [the instructor] makes it seem so easy because she gives you the lecturette, she gives you the transcript of the lecturette, and then we meet online and we can discuss. It's easy to understand. I can't believe it.

Ava described how she learned the material in this course by reviewing notes before class, summarizing chapters and writing down questions, going to class and following along on the PowerPoint slides, making notes, then asking questions in class or online. She would then feel prepared to apply the theory in practicum. Ava stated,

If I don't grasp like what the theory is saying ... I will just do it anyhow. But I mean, I will still get through. So, I don't want to do that. I'm not that type of learner. I want to fully understand it, to apply it.

Cheryl stated that knowing the expectations for all components of the course on the first day greatly contributed to her success in the course. She said, "Sometimes students are not really motivated to learn if they're not sure what the expectations are." For some the success was measured in marks; for others, the depth of understanding of the concepts provided a level of confidence to carry with them in their practicum and workplace.

Students did offer some suggestions to improve the course. One student commented that she would have liked the opportunity to hand in written assignments a second time. When she received grades and comments on her assignments, she felt she should have the opportunity to apply that feedback immediately, make improvements, and hand the paper a second time. This option was not offered in this course.

Cheryl stated she felt that this course should be a blueprint for all courses. The effectiveness in the design of this course emphasized how well a course could really work and accentuated the impediments to learning she was experiencing in other courses.

In summary, the results clearly demonstrate that students in this course found its design, based on UDL principles, to be highly effective in their ability to access materials. One-hundred percent of the respondents took advantage of the flexibility in being able to choose the weight of the final exam and availed themselves of the notes and presentations that were posted online well before class. Interview participants stated that the multiple means of accessing the materials greatly improved their understanding of the materials and others felt it contributed to their higher marks in this course. Students were accessing the same materials in multiple ways and were interacting with their peers and the instructor for deeper learning.

\section{Discussion}

\section{Impact of UDL-Inspired Course Design on the Instructor}

Overall, the incorporation of UDL-inspired course features led to a positive teaching experience for the instructor. Seeking different means of representing the course material helped her to view the topics in different ways, which prompted her to consider a variety of ways of explaining concepts. She was also more engaged (and likely more enthusiastic) as a teacher when including multiple means of representation in class sessions, compared to class sessions that more heavily focused on teacher-centred delivery of PowerPoint presentations. Having made available a variety of resources related to assessments on the 
WebCT site, students more commonly asked for feedback on drafts of their work and their understanding of the content rather than assessment expectations. Offering the optional short assignments was also positive from the teaching perspective because this allowed her to regularly touch base with the students and to have a clear idea of how the students understood the course material.

There were a few instances in which the UDL-inspired course features increased the teaching workload. For example, creation of multiple resources to aid in assignment completion was time consuming (though may have reduced student questions). Because previously prepared uncaptioned screencasts loosely based on scripts were used, creating accurate transcripts and captioning retroactively was more time consuming than if it had been done initially. Finally, as most of the class chose to work independently on the mandatory written report assignment rather than collaboratively, this led to an unanticipated large increase in workload for grading of the written report.

\section{Locus of Control}

Locus of control can be described as an outcome that is dependent on one's own behaviour versus the outcome being under the control of others (Rotter, 1990). Locus of control has several implications, and an internal locus of control has been positively associated with self-regulated learning as well as academic success (Keinan, 1987; Young, 2005). In the interviews, students described how they felt more in control of their learning by the choices they were given in the course, and it was evident that they felt their success in the course benefitted from the course design and the incorporation of the UDL principles and flexibility. As such, the design of the course provided an internal locus of control for students, and in doing so, enabled an environment for self-regulated learning.

An internal locus of control also contributes to the reduced stress felt by students, which was another theme that emerged from the interviews. Stress can have a negative impact on learning, for example, it can affect the ability to make rational judgments (Keinan, 1987), which can lead to activities such as academic dishonesty (Wideman, 2011). Students in this course stated that the course design contributed to a feeling of lower stress since they were able to see the requirements of the course, and plan how and when they would complete the requirements. They felt more in control of their learning and their academic success.

\section{Importance of Social Presence}

This course seemed to provide a high degree of social presence in that students reported feeling closely connected to the instructor and to each other. It was a learning environment that was supportive, personal, and caring. Students reported that the instructor was often available before and after class as well as online. They commented that the instructor sought out students she felt were struggling in an effort to determine how their learning could be improved. Social presence is an important contributor to the multiple means of engagement component of UDL. Moreover, students stated that this attribute improved their level of confidence, particularly in those who were returning to school after many years in the workplace. 


\section{Disability Services}

From an administration perspective, the design of this course reduced the need of the disability services department because content was available in multiple formats. For example, one student in the course disclosed to the instructor that she uses text-to-speech software for her studies. Since all course materials were designed to be fully readable by text-to-speech software, this eliminated the need for the disability services department to modify the course materials for this student. The study guides reduced the need for a learning strategist, as key concepts and review questions were available in the study guide. Note takers were not required as all the notes were available on the course site. The videos were captioned by the instructor. And the choice of types of assignment and assignment deadlines negated the need for advocacy on the part of the disabilities office to negotiate extended deadlines and alternative assignments with the instructor. One student indicated that she required additional time to complete tests, and although the professor offered tests and exams with extended time, this student chose to write her tests and exams in the university test centre, which provides a distraction-reduced testing facility.

\section{Limitations of This Study}

There were limitations to this study. First, it is difficult to assess how generalizable the data may be. One variable that may reduce the generalizability of the data is the small sample size. Data from a single three-credit hour course including $N=35$ study participants were presented. The number of study participants was small, and the data may not fully represent the experiences of the entire class $(N=50$ students) because not all students participated. Moreover, this study was a case study intended to capture the unique experiences of learners within this course, and the course attributes may not be feasible for inclusion in other courses (for example, different class sizes and/or different subjects). Another factor that may influence the generalizability of this study was the characteristics of the student participants. The student population that enrols in this course is likely to be more diverse and with different characteristics from other first-year undergraduate courses, and may therefore have different needs compared to other first-year students. While this diversity in student participants may enhance the richness of the data by offering a wide range of perspectives, it may not be representative of data that would be obtained from other first-year undergraduate students. Moreover, most students in this course were enrolled in their first semester at university and were enrolled in only two other courses concurrently. This left students with little ability to compare their experience in this course to other university courses that were not taught in a manner aligned with UDL.

A second limitation of this study was that students were informed of this study at the end of the term. Due to unforeseen delay in receiving ethics approval for the study, it was not certain that it would be possible to recruit student participants until very close to the end of the term. As such, students were not informed of the study and invited to participate until the last class. This allowed students little time to reflect on the course while completing the questionnaire, as they were asked to respond immediately after being informed of the study. Students may have formulated more thoughtful responses if they had known about the study and had been presented with the data collection instruments in advance. Students who volunteered to be interviewed did have more time to reflect on 
the course, though only four students came forward to be interviewed and they were not presented with the interview questions in advance.

\section{Conclusion}

The students participating in this study overwhelmingly took advantage of the UDLinspired course components, which provided multiple means of representation, engagement, and expression. Several students stated that this course should be a model for all others because they felt it assisted in reducing their stress by empowering them to make decisions such as assignment types, assignment weights, and due dates. They felt more in control of their learning as they determined which materials they would access that would best assist in their learning. These findings are consistent with other studies in the nascent body of UDL research.

The course incorporated a variety of learning strategies, enabling students to choose how and when they would learn materials. Moreover, the results of this study clearly indicate that UDL is beneficial to all students and not just students who identify as persons with disabilities. For students who had disabilities, the course design reduced their need to access the supports from the university's disability office. The internal locus of control enabled all students to develop learning strategies and processes that they would need to be successful in the course. This assisted in increasing the confidence of the students. According to the students, these factors lead to increased academic success and may, in turn, lead to improved retention of students.

\section{Future Research Directions}

Several approaches may be taken to further examine the relationship between UDL and student-perceived accessibility of postsecondary courses. With larger sample sizes, data collection instruments could be designed in a manner that would allow statistical analyses to be conducted (e.g., Likert-scaled questionnaires). The use of a different study design, such as a quasi-experimental design, could also be helpful. For example, in a multisection course, one class section could be exposed to UDL-inspired course design while a second class section could be taught in a more traditional prescriptive manner. This would allow for data from an experimental class to be compared to a control class and would help to further highlight the impact of UDL-inspired course delivery. Such examination could also include comparison of student learning outcomes (e.g., grades, student-perceived levels of understanding) across class sections designed with and without UDL in mind.

Future studies may also be aimed at further exploring trends observed in this study, such as the reasons behind the choices that students made in the course. For example, most students felt that the ability to work independently exceeded value in collaboration. It is unclear from this study if this choice was related to convenience of independent work or to other factors such as placing low importance on interdependence and connection with peers. 


\section{References}

Aerheart, B. (2008). When disability isn't "just right": Entrenchment of the medical model of disability and the Goldilocks dilemma. Indiana Law Journal, 83(1), 181-232.

American Association of University Professors. (2000). Does diversity make a difference? Three research studies on diversity in college classrooms. Washington, DC: American Council on Education.

American Council on Education. (2005). College students today-A national portrait. Washington, DC: American Council on Education.

CAST. (2011). About UDL. Retrieved from http://www.udlcenter.org/aboutudl

Coombs, N. (2010). Making online teaching accessible: Inclusive course design for students with disabilities. San Francisco, CA: Jossey-Bass.

Fichten, C. S., Jorgensen, S., Havel, A., \& Barile, M. (2006). College students with disabilities: Their future and success. Final report presented to FQRSC (Fonds de recherche sur la société et la culture). Retrieved from http://www.adaptech.org/cfichten/ abExecutiveSummaryCollegeStudentsWithDisabilities.pdf

Grace, S., \& Gravestock, P. (2009). Inclusion and diversity: Meeting the needs of all students. New York, NY: Routledge.

Hadley, H.M. (2011). College students with disabilities: A student development perspective. New Directions for Higher Education, 154(Summer). doi:10.1002/he.436

Harrison, E. (2006). Working with faculty toward universally designed instruction: The process of dynamic course design. Journal of Postsecondary Education and Disability, Special Issue: Universal Design in Higher Education, 19(2), 152-162.

Houghton, M., \& Fovet, F. (2012). Reframing disability, reshaping the provision of services. Report for the Canadian Association of College and University Student Services.

Hughes, B., \& Paterson, K. (1997). The social model of disability and the disappearing body: Towards a sociology of impairment. Disability \& Society, 12(3), 325-340.

Keinan, G. (1987). Decision making under stress: Scanning of alternatives under controllable and uncontrollable threats. Journal of Personality and Social Psychology, 52(3), 639-644.

Kumar, K. (2010). A journey towards creating an inclusive classroom: How Universal Design for Learning has transformed my teaching. Transformative Dialogues, 4(2).

Kumar, K. (2011). A learner-centred mock conference model for undergraduate teaching. Collected Essays on Teaching \& Learning, 4, 20-24.

McGuire-Schwartz, M. E., \& Arndt, J. S. (2007). Transforming Universal Design for Learning in early childhood teacher education from college classroom to early childhood classroom. Journal of Early Childhood Teacher Education, 28(2), 127-139.

National Center for Education Statistics. (2011). The condition of education 2011. Retrieved from http://nces.ed.gov/programs/coe/index.asp 
National Council on Disability. (2003). People with disabilities and postsecondary education-Position paper. Retrieved from http://www.ncd.gov/publications/2003/ Sept152003

Oliver, M. (1996). Understanding disability: From theory to practice. Houndmills, UK: Macmillan.

Orkwis, R., \& McLane, K. (1998). A curriculum every student can use: Design principles for student access. OSEP Topical Brief. Reston, VA: Council for Exceptional Children.

Parker, D. R., Robinson, L. E., \& Hannafin, R. D. (2007). "Blending” technology and effective pedagogy in a core course for preservice teachers. Journal of Computing in Teacher Education, 24(2), 61-66.

Roberts, K. D., Park, H. J., Brown, S., \& Cook, B. (2011). Universal Design for Instruction in postsecondary education: A systematic review of empirically based articles. Journal of Postsecondary Education and Disability, 24(1), 5-15.

Rose, D. H., Harbour, W. S., Johnston, C. S., Daley, S. G., \& Abarbanell, L. (2006). Universal Design for Learning in postsecondary education: Reflections on principles and their application. Journal of Postsecondary Education and Disability, 19(2), 135-151.

Rose, D. H., \& Meyer, A. (2002). Teaching every student in the digital age: Universal Design for Learning. Alexandria, VA: ASCD.

Rotter, J. B. (1990). Internal versus external control of reinforcement: A case history of a variable. American Psychologist, 45(4), 489-493.

Sapp, W. (2009). Universal design: Online educational media for students with disabilities. Journal of Visual Impairment \& Blindness, 103(8), 495-500.

Terzi, L. (2004). The social model of disability: A philosophical critique. Journal of Applied Philosophy, 21(2), 141-157.

U.S. Government Accountability Office. (2009). Higher education and disability: Education needs a coordinated approach to improve its assistance to schools in supporting students (No. GAO-10-33). Retrieved from http://161.203.16.70/products/GAO-10-33

Wideman, M.A. (2011). Caring or collusion: Academic dishonesty in a school of nursing. The Canadian Journal of Higher Education 41(2), 28-43.

Wilkoff, W., \& Abed, L. (1994). Practicing universal design: An interpretation of the $A D A$. New York, NY: Van Nostrand Reinhold.

Young, M.R. (2005). The motivational effects of the classroom environment in facilitating self-regulated learning. Journal of Marketing Education, 27(1), 25-40. 


\section{Appendix A}

\section{Sample Student Questionnaire}

\section{PART I: Course Materials}

Please circle "Yes" or "No" to indicate which of the course materials listed below you accessed, and whether or not they were helpful.

\begin{tabular}{|l|c|c|c|c|}
\hline Course Material & \multicolumn{2}{|c|}{ Accessed? } & \multicolumn{2}{c|}{ Helpful? } \\
\hline Text descriptions of images in PowerPoint files & Yes & No & Yes & No \\
\hline PDF printer-friendly version of PowerPoint notes & Yes & No & Yes & No \\
\hline Detailed topic outlines in study guides & Yes & No & Yes & No \\
\hline Lists of key concepts in study guides & Yes & No & Yes & No \\
\hline Video recording of sample oral presentation & Yes & No & Yes & No \\
\hline Transcript of sample oral presentation & Yes & No & Yes & No \\
\hline Text-only version of sample poster presentation & Yes & No & Yes & No \\
\hline Video poster preparation tutorial & Yes & No & Yes & No \\
\hline Captions in video poster preparation tutorial & Yes & No & Yes & No \\
\hline Transcript of video poster preparation tutorial & Yes & No & Yes & No \\
\hline Video recording of microbiology lecture & Yes & No & Yes & No \\
\hline Transcript of microbiology lecture & Yes & No & Yes & No \\
\hline
\end{tabular}

Of the course materials above that you accessed, which was the MOST helpful? Explain why this material was particularly helpful to you.

Most helpful course material:

Why this was helpful: 


\section{PART II: COURSE ATTRIBUTES}

Please circle "Positive" or "Negative" to indicate whether the impact course attributes listed below were positive (helped you to succeed), negative (hindered your success), or none (had no effect).

\begin{tabular}{|l|l|l|}
\hline Course Attribute & \multicolumn{2}{|c|}{ Impact? } \\
\hline Choices for written report due dates & Positive & Negative \\
\hline $\begin{array}{l}\text { Choice to work independently or collaboratively on some as- } \\
\text { sessments }\end{array}$ & Positive & Negative \\
\hline Choice for presentation format (oral or poster presentation) & Positive & Negative \\
\hline Choice for presentation date & Positive & Negative \\
\hline Posting of class notes and study guide prior to the relevant class & Positive & Negative \\
\hline $\begin{array}{l}\text { Repetitive organization format of course materials WebCT } \\
\text { pages }\end{array}$ & Positive & Negative \\
\hline $\begin{array}{l}\text { Ability to choose whether to complete optional activities or } \\
\text { write a final exam worth more marks }\end{array}$ & Positive & Negative \\
\hline $\begin{array}{l}\text { Instructor's request to submit a Student Profile form at the be- } \\
\text { ginning of the term }\end{array}$ & Positive & Negative \\
\hline
\end{tabular}

Of the attributes listed above that you found helpful, which was the MOST helpful? Explain why this attribute was most helpful to you.

Most helpful course attribute:

Why this was helpful:

Do you consider yourself to be a student with a disability? Please circle: YES NO 


\section{Appendix B \\ Semi-Structured Interview Protocol}

Thank you for agreeing to be interviewed for this study. It will be very helpful to learn from you about what may help to make a course more accessible for students.

I'm going to ask you a few questions about your needs and preferences with respect to the way that courses are designed. There aren't any right or wrong answers-it's your experiences and opinion that the questions are related to. You are free to decline to answer any questions if you choose, and if you wish to stop the interview at any time, simply let me know.

This interview is related to course accessibility, so I'd like to share with you a definition of accessibility before asking you your thoughts on it. One way to define an accessible course is as a course where all students have the ability to access the content and the potential to perceive and understand the content. For example, if information is posted in WebCT, all students should be able to find and open or download the content, and also use the content (e.g., by reading or listening to it). It should also be possible for all students to have the ability to express their understanding of content, and therefore course assignments should also be accessible to all students. In general, accessible courses tend to be flexible.

\section{Part I: General Questions}

The first few questions are general questions about course accessibility and your related opinions and experiences.

1. Based on this definition of accessibility, is accessibility of a course something that is important to you?

2. Have you ever had an experience when a more accessible (flexible) course would have benefitted or detracted from your learning? Tell me about that.

3. In general, what features do you associate with an accessible course? For example, what aspects of a WebCT site, course materials, or assignments make them accessible to you?

4. In general, what features do you associate with an inaccessible course? For example, what aspects of a WebCT site, course materials, or assignments make them difficult for you to access, understand, or complete?

5. Have you ever requested that changes be made to a course to make it more accessible? How did you do that? What was the response?

6. If you were to design a course that was completely accessible to you, what features would you include in the course design, materials, or assignments, and why?

7. Is there anything else about course accessibility that you'd like to tell me about? 


\section{Part II: Specific Questions}

The last few questions are related to the questionnaire that you completed in the class.

1. In the questionnaire, you were asked to comment on which course materials you accessed and whether or not they were helpful to you.

a. As you look at the questionnaire now, which of the course materials listed were most helpful to you and why?

b. Were there other materials or attributes of materials that you found helpful that you'd like to comment on?

2. In the questionnaire, you were asked to comment on which aspects of the course design helped or hindered your success.

a. As you look at the questionnaire now, which of the course design aspects listed did you feel were not helpful or may even have hindered your success in the course?

b. Were there other course attributes that you'd like to comment on?

3. Is there anything else related to accessibility of this course that you'd like to tell me about? 


\section{Contact Information}

Faculty of Extended Education

University of Manitoba

Kari.Kumar@umanitoba.ca

Kari Kumar has a PhD in Education from York University, Toronto, where her research on e-learning accessibility evaluation was conducted at the Institute for Research on Learning Technologies. She has also received a BSc and MSc from the Department of Microbiology at the University of Manitoba, Winnipeg. Her research interests include e-learning accessibility and inclusive design, and she has taught various postsecondary courses in the life sciences.

With a PhD in curriculum, teaching, and learning, Maureen Wideman's expertise involves curriculum development as well as inclusive learning environments. As a faculty development consultant, she has mentored faculty members in program planning, learning with technology, curriculum design, and accessibility. She has participated in the research and development of universal learning principles in education. She has recently taken on the role of Director of Teaching and Learning at the University of the Fraser Valley. 